\title{
The Impact of Prior Exposure to Calculus
}

\author{
Matthew R. Schraeder ${ }^{*}$, Laura J. Pyzdrowski, David A. Miller \\ Department of Mathematics, West Virginia University, Morgantown, WV, United States \\ *Corresponding author: mrschraeder@mix.wvu.edu \\ Received January 12, 2019; Revised February 24, 2019; Accepted March 12, 2019
}

\begin{abstract}
Many students who take calculus in high school opt to retake the course in college. This study investigated the impact of that prior exposure. Students were invited to complete a survey about their experiences with calculus, with eight being interviewed afterwards. While students nearly unanimously agreed that prior experience with calculus was a benefit, none felt that it was a necessity to succeed in a college calculus course. Also, a few students identified some detriments to having taken calculus in high school, mostly stemming from an inadequate high school class. Despite the students' perceptions, Pearson's Chi Square Tests identified a significant difference in both the students' success (pass/fail) and letter grades based on the method of placement into Calculus I (testing in via a placement test did better than taking the pre-requisite courses), but not based on either prior exposure to calculus or type of calculus taken during high school (AP and taking the test, AP and not taking the test, non-AP, or no calculus). A survey on student perceptions identified calculus as the most beneficial class to take before Calculus I, but interviews indicated algebra and trigonometry as the most beneficial.
\end{abstract}

Keywords: calculus, AP, success, prior experience, algebra, trigonometry, placement

Cite This Article: Matthew R. Schraeder, Laura J. Pyzdrowski, and David A. Miller, "The Impact of Prior Exposure to Calculus." American Journal of Educational Research, vol. 7, no. 3 (2019): 237-243. doi: 10.12691/education-7-3-8.

\section{Introduction}

Calculus is a required class for many majors. Historically, students have failed to pass the class at a shockingly high rate. Reference [1] found that more than $40 \%$ of college calculus students fail. Reference [2] found that the number was more than $50 \%$ when including those who withdrew from the class. Contrarily, [3] found that the DFW rate (the percentage of students earning the grades of " $D$ " or " $F$ " or withdrawing from a course) was slightly less than $22 \%$, based on data from 197 institutions. However, the DFW rate at the researchers' institution has been approximately $40 \%$ over the past four years (never dropping below $32 \%$ ), so the low rates were not seen everywhere. Many studies have investigated student performance in calculus. One potential contributing factor is prior knowledge from previous math courses, whether that is exposure to the concepts of calculus (or a lack thereof) or various pre-calculus subjects. As noted in a Mathematical Association of America (MAA) study, the Characteristics of Successful Programs in College Calculus, about one-third of students who take calculus in high school take it again in college [4]. Given this information, the impact of that prior exposure to calculus proved to be intriguing.

The purpose of this study was to investigate the impact of prior exposure to calculus on students in a college Calculus I class. There were three main research questions. 1) Do students enrolled in their first on-campus Calculus I course, who have been directly placed via placement criteria, have better end-of-course grades than students placed with pre-requisite coursework? 2) Do students enrolled in their first on-campus Calculus I course who have prior exposure to Calculus (in some form) have better end-of-course grades than students with no previous Calculus experience? 3) Do students enrolled in their first on-campus Calculus I course, who have no prior exposure to Calculus, feel they are at a disadvantage when compared to students with previous Calculus experience; and why or why not? The answers to these questions could provide valuable insight into role that prior exposure to calculus plays in the mathematical experiences of college students. Whether producing observable differences or merely impacting the psyches of students, prior exposure to calculus may have a real impact on students.

\section{Review of Related Literature}

Various studies have offered recommendations for how to remedy the less-than-desirable situation surrounding student success in college calculus, mostly aiming to either change the structure of the class or to offer help via academic support. Reference [2] conducted a study pertaining to teaching styles. Interestingly, he claimed that while many students lamented uninteresting teaching styles, others preferred the standardization of those same teaching techniques. In the same study, [2] also pointed to students' poor pre-calculus preparation in mathematics, rather than the instruction of calculus courses, as a culprit 
to their lack of success. The change suggested by [2] is for pre-calculus courses to be more rigorous and detailed, rather than changing the actual calculus courses being offered.

Reference [5], on the other hand, did call for change in the college calculus courses in his study at the University of New Hampshire. He claimed that high school calculus courses are not sufficient enough to preclude the need for students to take the first-year calculus course in college. However, he posited that students are not being challenged appropriately during their second time through calculus, and that those students who are in the course for the first time can be disadvantaged with the accommodations being made for the growing numbers who have previous experience with the material. Neither group of students, those with or those without prior exposure to calculus, are in an appropriately structured course. These students who have had calculus while in high school find themselves in a unique (and perplexing) situation. They are not fully challenged by Calculus I, but are not yet ready for Calculus II.

Reference [4] addressed the theme of high school students rushing to calculus, noting that there is strong anecdotal evidence from teachers at both the high school and university level that many of these students are shortchanging their preparation in middle and high school mathematics to join the fast track to calculus. Again anecdotally, this appears to be a significant problem when students attempt a math-intensive major where weaknesses in pre[-]calculus material can be disastrous. (para. 9).

His recommendation was that building a firm understanding of the basics of mathematics outweighs the push to reach more advanced courses in less time.

Despite generally doing well in college calculus, [5] revealed that students with a year of high school calculus are not overqualified for a first semester calculus course in college. In addition, he found that students with little previous exposure to calculus did not perform well when taking calculus for the first time. Therefore, while prior calculus experience may not be an overwhelming advantage, a lack of it appears to be a fairly real hindrance. Reference [5] also found that competency in algebra and trigonometry was a factor in the success of first-semester calculus students.

Reference [6] investigated the calculus backgrounds and calculus performance of first-year college calculus students. Results showed that students who studied a full year of calculus in high school were more successful in the course than students with either limited or no calculus experience. Additionally, there was no statistical difference in performance between students who had a year of calculus and those who reported an Advanced Placement (AP) course while in high school, so the type of high school calculus class appears to be inconsequential. Students in Advanced Placement courses follow a structured curriculum and take an exam for possible college credit upon completion of the course.

It was reported that prior experience with calculus concepts was among the main factors that can influence student success in entry-level calculus, and that even those who passed college algebra and college trigonometry as pre-requisite courses did not always perform well [7]. Reference [5] surveyed 741 first semester calculus students and found that the group most at risk for not passing calculus had no previous calculus experience and could not pass a calculus pre-test on algebra and trigonometry. One may conclude that while a strong background in algebra and trigonometry is preferred, it may not be enough to help a student with no calculus experience pass a college calculus class. Obviously, a lack of exposure to calculus is not an impossible obstacle to overcome for everyone, but it is an insurmountable barrier to many.

Recent studies used student interviews to gain a deeper understanding about students' success in and preparation for calculus. Four students were interviewed regarding their preparation for calculus. Four themes related to success in calculus were identified in the analysis of student interviews: a) Prior Course Work, b) Experience with Calculus, c) Getting Help, and d) Pace of the Course and Instructors. All interviewees said that they felt appropriately placed into Calculus I based on the success experienced in prior course work in college algebra and trigonometry courses. However, after completing the calculus course, only three of the four students felt that the courses sufficiently prepared them. In addition, two of the four students who were interviewed had prior work in calculus. Although one interviewed student felt that just having the college algebra and trigonometry courses would have been enough to allow for success in Calculus I, both interviewed students who had not taken calculus in high school recommended that students take it in high school before attempting Calculus I as an entry-level college course [8]. In small follow-up studies, student interviews revealed that success in a Calculus I course was attributed to the fact that all of the concepts had already been learned in a high school calculus course; and, that having previous experience with calculus was perceived to be a benefit $[8,9]$.

The preponderance of evidence supporting the preference for prior participation in a calculus class is overwhelming and should be investigated more closely. While it appears to be fairly obvious that prior experience with calculus concepts is a factor that could influence student success in entry-level calculus, the nature of the predicament is in doubt. Research is needed to determine if the failure to pass calculus is related to students' perceptions of being at a disadvantage, or if students really are at a disadvantage when they have no prior experience in calculus.

In an analysis of college instructor interviews, it was found that in addition to prior experience with calculus, students' understandings of pre-requisite material was a strong indicator of their success in calculus. Adding statistical backing to the instructors' beliefs, it was determined that a Calculus Readiness Assessment which tested students on algebra, trigonometry, and pre-calculus had a significant positive correlation with course performance in Calculus I [8]. These findings supported the information that was disclosed by [5] concerning indicators of success, particularly as it relates to background knowledge in mathematics.

Given the growing number of students experiencing calculus in high school, the purpose of this study was to investigate the impact of prior course work (such as algebra and trigonometry, and, in particular, exposure to calculus) on students' performance in a college Calculus I class. 


\section{Method}

\subsection{Participants}

The eligible students for this study were the 651 Calculus I students (not including those who withdrew from the class) at a Land Grant university in the Eastern United States. Calculus I at this institution is divided into Engineering (436 students) and Non-Engineering (215 students). The learning outcomes for both versions of the course are identical, though the Engineering sections focus on the application problems toward the engineering field. All students were invited to complete an on-line survey towards the end of the Fall 2015 semester. From all of the possible students, 125 (40 Engineering and 85 Non-Engineering) completed the survey, of which 54 (20 Engineering and 34 Non-Engineering) agreed to be interviewed.

The 54 eligible students were divided into subgroups based on specific demographic information with students randomly chosen from those subgroups. Three criteria were used to create the subgroups: prior exposure to calculus, type of class (Engineering versus Non-Engineering), and grade (A-C versus D-F). Student grades were obtained from the instructors and not self-reported by the students. A total of sixteen students were contacted from the eight possible subgroups. Eight interview subjects agreed to participate in the study (Table 1).

Table 1. Subgroup Characteristics

\begin{tabular}{|c|c|c|c|}
\hline Students & $\begin{array}{c}\text { Prior Calculus } \\
\text { Exposure }\end{array}$ & $\begin{array}{c}\text { Type of Calculus I } \\
\text { Class Taken }\end{array}$ & $\begin{array}{c}\text { Grade in } \\
\text { Calculus I }\end{array}$ \\
\hline B, C & Yes & Engineering & A-C \\
\hline E & Yes & Engineering & D-F \\
\hline D es & Yes & Non-Engineering & A-C \\
\hline & No & Engineering & A-C \\
\hline A , G & No & Engineering & D-F \\
\hline F, H & No & Non-Engineering & A-C \\
\hline
\end{tabular}

The interview subjects were as follows:

Student A - A in Non-Engineering, never took Calculus before, male

Student B - A in Engineering, took AP Calculus in high school, female

Student C - B in Engineering, took Non-AP Calculus in high school, male

Student D - D in Non-Engineering, took AP Calculus in high school, female

Student E - B in Non-Engineering, had failed Calculus

I 17 years before, male

Student F - D in Non-Engineering, never took Calculus before, female

Student $\mathrm{G}-\mathrm{C}$ in Non-Engineering, never took Calculus before, male

Student $\mathrm{H}-\mathrm{D}$ in Non-Engineering, never took Calculus before, male

\subsection{Instruments}

An on-line survey and an interview protocol were used in this study. The primary author developed each by adapting instruments used in previous studies. Both the survey and interview protocol were then reviewed by the two co-authors and deemed to be valid.

The on-line survey was fairly short (11 questions) and was aimed at gaining some background information (prior classes taken) and opinions (how students studied, what prior classes were helpful, which topics were difficult) from the students. Some questions were multiple-choice (with a few allowing one selection and others multiple answers), but others were free-response.

The scripted interview questions were designed to expand upon the survey questions and allowed the students to elaborate upon their answers. Unplanned follow-up questions were asked when deemed necessary to elicit further information.

\subsection{Design and Procedure}

At the end of the Fall 2015 semester, students in Calculus I (both Engineering and Non-Engineering) were asked (via e-mail) to participate in an on-line survey about their experiences in calculus, and focusing on their experience (if any) before taking Calculus I in college. Students were given slightly more than two weeks to complete the survey.

Students were divided into different subgroups to increase the chances that various perspectives were obtained from the interviews (due to students having different characteristics and experiences). Age, gender, year in college, and other demographic details were not addressed in the survey to keep it shorter, with the hope of increasing the response rate. Also, this demographic information did not fit the scope of this study, so the information was not sought.

All interviews were conducted by the primary researcher within the first three weeks of the Spring 2016 semester in that researcher's on-campus office.

\subsection{Data Analysis}

Driven by the findings of prior research, the survey included questions pertaining to prior math classes taken (both calculus or pre-calculus courses), other math classes that had to be repeated, and whether having prior calculus experience was perceived to be a benefit. Additionally, this study investigated which topics the students perceived to be the most difficult in Calculus I in order to better understand the relevance of pre-requisite course work. The survey results were examined to determine trends and commonalities among the students.

Pearson's Chi Square Test was used to analyze the survey data because that test is used to determine whether a relationship between two variables was due to chance, which was the purpose of the data analysis. Six comparisons were made:

- prior calculus experience (yes or no) versus pass/fail in Calculus I

- type of high school calculus experience (AP class and took the test, AP class and did not take the test, 
non-AP class, no high school calculus) versus pass/fail in Calculus I

- prior calculus experience versus letter grade in Calculus I

- type of high school calculus experience versus letter grade in Calculus I

- method of entry into Calculus I (placement test or pre-requisite class) versus pass/fail in Calculus I

- method of entry into Calculus I versus letter grade in Calculus I.

The method of entry into Calculus I was obtained from the survey question about any previous college math classes taken. If no previous classes were listed, then the student was determined to have been placed into Calculus I by the departmental placement test or Math ACT/SAT score.

The student interviews were audio recorded. All interviews were transcribed, with all three researchers independently analyzing them, searching for key words and phrases using in vivo open coding techniques [10] to identify themes that emerged for the group, such as advantages of taking calculus previously, disadvantages of taking calculus previously, the most beneficial prior class taken, and the most difficult topic in calculus. The researchers then met to discuss any commonalities or discrepancies in the analyses. The emerging themes were identified with few disagreements, all of which were minor and could mainly be attributed to the name of the label used. After the interview data were collected and coded, any trends that were noticed were compared to the trends from the surveys. Consistencies and discrepancies were noted. The analysis of the interviews was used to address research question \#3.

\section{Results}

The surveys revealed some overwhelmingly one-sided responses (Table 2). Of the 119 students who responded to the question about how they primarily studied (alone, with 1-2 others, with 3-5 others, or with more than 5 others), 93 studied alone. One-hundred fourteen students responded to the question about the class that helped them prepare the most for Calculus I, with 63 crediting calculus. One-hundred nine of 117 students felt that prior exposure to calculus would be beneficial, and 85 of 117 believed that not having prior calculus experience would be a disadvantage. Optimization, related rates, and application problems were deemed to be similar in composition (requiring similar skills, techniques, and procedures), so they were treated as a single topic. This triad was identified as the most difficult topics by the most students (a plurality, but not a majority), followed by limits. No patterns for the most difficult topic could be identified based on prior experience in calculus or grade in Calculus I.

The Pearson's Chi Square Tests were only statistically significant for two of the six comparisons. The tests comparing prior calculus experience versus pass/fail in Calculus I $\left(\chi^{2}(1)=2.274406, p>.05\right)$, type of high school calculus experience versus pass/fail in Calculus I $\left(\chi^{2}(3)=5.400793, p>.05\right)$, prior calculus experience versus grade in Calculus I $\left(\chi^{2}(4)=5.946852, p>.05\right)$, and type of high school calculus experience versus grade in Calculus I $\left(\chi^{2}(12)=20.85436, p>.05\right)$ were all not significant. However, method of entry into Calculus I versus pass/fail in Calculus I $\left(\chi^{2}(1)=6.754047, p<.01\right)$ and method of entry into Calculus I versus grade in Calculus I $\left(\chi^{2}(4)=16.27995, p<.01\right)$ were both significant. Using the odds ratios, those who tested into the class were 3.6 times more likely to pass that class than those who took the pre-requisite classes.

Table 2. Survey Results from 117 Respondents

\begin{tabular}{|l|l|c|c|c|c|}
\hline \multicolumn{2}{|l|}{ How Studied Most } & \multicolumn{2}{c|}{ Most Beneficial Prior Class } & \multicolumn{2}{c|}{$\begin{array}{c}\text { Prior Calc } \\
\text { Beneficial }\end{array}$} \\
\hline Alone & 93 & Calculus & 63 & Yes & 109 \\
\hline With 1-2 others & 23 & Algebra & 22 & No & 5 \\
\hline With 3-5 others & 2 & Trigonometry & 16 & Some & 3 \\
\hline $\begin{array}{l}\text { With more than 5 } \\
\text { others }\end{array}$ & 1 & None & 12 & & \\
\hline & & Pre-Calc & 9 & & \\
\hline $\begin{array}{l}\text { No Prior Calc } \\
\text { Hurt }\end{array}$ & 85 & $\begin{array}{c}\text { Optimization, Related } \\
\text { Rates, Application }\end{array}$ & 46 & & \\
\hline Yes & 21 & Limits & 22 & & \\
\hline No & 7 & $\begin{array}{l}\text { Riemann Sums, } \\
\text { Sigma Notation }\end{array}$ & 13 & & \\
\hline Some & 4 & Integrals & 11 & & \\
\hline Depends & Derivatives & 8 & & \\
\hline & Miscellaneous & 33 & & \\
\hline & & & & & \\
\hline
\end{tabular}

Notes: Some students offered more than one answer for the Most Beneficial Prior Class and Most Difficult Topic.

The Pre-Calculus course at the university where the study was conducted is a combination of Algebra and Trigonometry, so students who had that class were counted as both Algebra and Trigonometry, not Pre-Calculus. Fewer than five students chose any of the 12 individual topics listed as Miscellaneous.

Several themes emerged from the interviews, which were conducted early in the Spring 2016 semester. First, three of the four students who had prior exposure to calculus (Students B, C, D) felt that it was a benefit, and three of the four students who did not have calculus before (Students F, G, H) commented that prior experience in general (whether in calculus or another class) would be beneficial when taking that class again. All four students who did not have calculus before (Students A, F, G, H) agreed that the lack of exposure to calculus was a disadvantage for them.

Surprisingly, three of the four students who had calculus before (Students B, D, E) stated that having calculus before taking it in college also hurt them, but for different reasons. Student B said, "It kind of hurt me because I had learned some of the concepts differently... 
My teacher had taught concepts a little differently, and then the professor here would teach them more in depth, and I would be confused or trying to understand it a different way." Student D found that her previous calculus class was inadequate: "But it hurt because it [the high school calculus] was all calculator-based, and so I didn't actually learn how to solve anything." She later added: "To be honest, it [high school calculus] kinda gave me the impression that [Calculus I] was going to be lot easier. That was wrong." Student E was a non-traditional student who had briefly attended college after high school, and was now returning. Of his prior experience with calculus, he stated, "I got absolutely nothing from it. Let's just say that school was not a priority at the time."

All eight students agreed that, even though students who have had prior experience with calculus had an advantage and those who did not have prior experience were disadvantaged, taking calculus previously was not a necessity to succeed in Calculus I. Student A and Student $\mathrm{G}$ cited themselves as proof of this: they both passed Calculus I on their first try without any prior exposure to calculus. The students who did not pass Calculus I (Students $\mathrm{F}$ and $\mathrm{H}$ ) felt that success was possible, despite their lack of accomplishment. The general consensus was that hard work and other mathematical abilities could overcome the lack of direct calculus knowledge.

Contradicting the results from the survey (in which the majority listed calculus as the most helpful class prior to taking Calculus I), only two of the students who were interviewed (Students B and C) mentioned calculus. Rather, five listed algebra (Students A, D, E, F, G) and four chose trigonometry (Students D, E, G, H). Student E also mentioned geometry as being the most helpful. He explained the multiple responses: "They all taught different components. I need geometry, I need trigonometry, and I need algebra to do calculus, don't I?" Student D had a similar explanation, but focused more on trigonometry: "Definitely be good at trig. Be good at trig. Know your algebra. Be able to do stuff without a calculator. Taking high school calculus might help a little bit, but, overall, it was the trig."

Potentially calling these results into question, four of the interviewed students changed their answers (somewhat, at least). Both Student $C$ and Student $F$ wrote that no class was most beneficial in preparing for Calculus $I$ in the survey. Student D listed calculus, and Student E only listed algebra and geometry (omitting trigonometry). This begs the question as to whether other students would have changed their answers if given the chance to verbalize their thoughts.

Optimization, related rates, and application problems were still mentioned the most as the most difficult topics in Calculus I, with three (Students E, F, G) of the eight students mentioning them (in some form). As with the survey, no patterns emerged for this inquiry. However, trigonometry (Students A and F) and hyperbolic functions (Students B and C) were each listed by two students. It must also be noted that Student $F$ listed several topics in the interview as being the most difficult, but limits (in particular) confounded her.

Somewhat expectedly, all eight students reported that they did practice problems as part of their studying routines, and all predominantly studied alone. However, a rather subtle theme of metacognition (particularly the students' awareness about how they learn best) was noted. Students A, B, and G (who all passed Calculus I) each stated that they were cognizant of how they studied and offered a justification for why they studied that particular way. Contrarily, Students D and F (who did not pass Calculus I) did not know why they studied the way that they studied. Students C, E, and H did not broach the subject.

In addition to doing practice problems, Student $\mathrm{A}$ also reviewed his notes, seeking help when he needed it (whether from his instructor, a tutor, or Khan Academy). In emphasizing the practice problems, Student A said, "I like to do stuff like that as well because that's how I learn. I learn by doing as opposed to looking back over things I've already done. Just do as many as I can." Beyond doing practice problems and merely reviewing her notes, Student B rewrote her notes, stating, "Writing my notes again is how I learn. I learn through writing." Student G lamented not studying with others for Calculus I (as he had done in previous courses). When studying in a group, Student G said, "I would end up reviewing the material that I learned myself with them to try and help them. So, ultimately, I would learn better by explaining it to them. And I didn't do that too much in [Calculus I] at all."

On the other end of the metacognitive spectrum, Student D only did practice problems, but did not benefit from them. He explained, "I didn't really get any [advantage]. I just ended up being more confused." Student F did the only thing that she could think of: "I looked over the labs, over the quizzes, and things like that. I never used the textbook. I probably should have done that. That's how I studied because that's how I always used to study for math. Apparently, it didn't pay off very well."

\section{Discussion}

Although the population for this study was primarily comprised of white Americans (and not African-Americans), the survey and interview results supported the findings of [11] that students tend to study alone. [11] went on to note that poor performance in calculus has been identified as a barrier to those majoring in fields that depend upon mathematics. The students in this investigation did study in small groups at times, but usually only when they needed help (as Student C stated). Some other justifications were offered for studying alone. Student D felt a bit of despair and helplessness: "No one else knew what was going on. It wouldn't have helped." Student F also cited a lack of a reliable study partner, and Student $\mathrm{H}$ procrastinated, so others had already finished studying by the time he started. Student E worked a full-time job, so his schedule differed from that of most students. Couple that with an age difference (Student $\mathrm{E}$ was a nontraditional student), and a barrier is readily noticed. Student $\mathrm{G}$ regretted not studying with others.

The overwhelming majority of the students (from both the survey and the interviews) felt that having prior exposure to calculus before taking Calculus I was an advantage and that not having prior exposure to calculus before taking Calculus I was a disadvantage. These findings corresponded with those stated in other studies 
$[8,9]$. However, none of the students who were interviewed felt that this prior exposure was needed to pass Calculus I, which agreed with the findings of [7]. Rather, solid foundations in algebra and trigonometry were deemed to be more beneficial (coupled with hard work). [5] and [8] found evidence to support the importance of algebra and trigonometry when taking calculus. This revelation contradicted the survey results, in which students mostly listed calculus as the most beneficial class for Calculus I.

The intriguing part of this is that four of the eight students who were interviewed changed their answers for this question from what they offered in the survey. Of course, Student $\mathrm{C}$ changed his answer from "N/A" to calculus (which agreed with the majority from the survey) and Student F changed from "none" to algebra. Student E merely added trigonometry to algebra and geometry, but Student D made the big switch, changing from calculus to algebra and trigonometry. The reason for these changes requires further investigation. Did the students just change their minds? Did their true beliefs reveal themselves in the process of thinking deeply and voicing their opinions during the interview (whereas they offered spontaneous answers on the survey without reflecting thoughtfully)? Would other students also change their answers?

Another disclosure from the interviews was the revelation that taking calculus before taking Calculus I could actually be a detriment. One student was confused by seeing the material presented in a different way the second time. Two other students cited inadequate calculus courses in high school, corroborating the findings of [5]. [6] noted that offering a "watered down" calculus class in high school is undesirable conveying a "watered down" course as one heavy with manipulations. Their conclusion was that a focus on procedure can inhibit the acceptance of the conceptual emphasis often found in a college course. The Mathematical Association of America's Committee on the Undergraduate Program in Mathematics also lamented a less-than-comprehensive calculus class as being on par with offering no calculus class at all [6]. If a calculus class is going to be offered (and the argument was for offering it), then it should be on the level of an Advanced Placement class.

The Pearson's Chi Square Tests found that neither prior experience with calculus nor the type of calculus taken in high school significantly affected whether a student passed Calculus I, or even the letter grade received in Calculus I. This corroborated the findings of [6] that no significant difference existed between students who took Advanced Placement calculus and those who took nonAdvanced Placement calculus when the students took calculus in college. However, the path that a student took to get into the class in this study (departmental placement test or pre-requisite classes) made a significant difference in both whether the student passed Calculus I and the student's overall letter grade in Calculus I, with those who placed into Calculus I via some placement criteria performing better than those who took the pre-requisite classes.

There are two obvious potential reasons for this inconsistency in success. First, the pre-requisite courses at the university could be inadequate in preparing students for Calculus I. But, it is worth noting that the algebra, trigonometry, and pre-calculus classes at the university are comparable to similar courses at other institutions. The departmental courses of algebra, trigonometry, precalculus and first semester calculus recently went through a review process at the state level to verify this fact. Also, significant attention is given to meeting the needs of students in the course pathways; however, it is anticipated that there will be an ongoing study pertaining to this conjecture. The authors suggest that the second more likely explanation is due to a disparity in ability between the two groups of students; placement criteria into calculus has gradually been increased over the past several years at the institution. This has been done, in part, by administrators trying to impact the success rate of students in the course. The implication is that students who have the ability to test directly into Calculus I are stronger mathematically than those who must take the pre-requisite classes. As a result, these more-capable students are more likely to succeed in the more-difficult class. However, the possibility exists that the placement test standards were too high, artificially inflating the success rate for those who placed directly into Calculus I by only allowing the most-capable students to bypass the pre-requisite classes. Please note that regardless of the reason why a difference in success rates exists, students who take the pre-requisite classes are still capable of passing Calculus I; results show that they are simply less likely to do so.

The metacognitive aspect discovered in the interview analysis is intriguing and also merits further investigation. From this limited study, it appears as though an awareness of how one learns can impact how well a student does in a calculus class. Future studies will be designed to delve into this revelation in order to pursue this finding with greater vigor.

\section{Limitations}

The population of students available for this study was restricted to those who were available to the researchers, thereby making it a convenience sample. Even through there were 651 students eligible for the study, the demographics of the students who ultimately participated were somewhat narrow. For example, the vast majority of students who completed the survey received a passing grade in the class. Therefore, the opinions of students who failed Calculus I may not have been fully and completely exposed.

Similarly, three subgroups were not interviewed: students who did not pass Engineering Calculus, but had calculus in high school, and students who took Engineering Calculus (whether they passed or failed) and did not have calculus in high school. Only three Engineering Calculus students who completed the survey did not have calculus in high school (one pass and two fail), and all declined to be interviewed. Only one student who completed the survey took Engineering Calculus, and had calculus in high school failed Calculus I, and (again) declined to be interviewed.

\section{Conclusion}

The research questions in this study were: 1) Do students enrolled in their first on-campus Calculus I 
course, who have been directly placed via placement criteria, have better end-of-course grades than students placed with pre-requisite coursework? 2) Do students enrolled in their first on-campus Calculus I course, who have prior exposure to Calculus, have better end-of-course grades than students with no previous Calculus experience? 3) Do students enrolled in their first on-campus Calculus I course, who have no prior exposure to Calculus, feel they are at a disadvantage when compared to students with previous Calculus experience; and why or why not?

The findings from this study indicated that how students were placed into Calculus I had a significant impact on both whether the students passed Calculus I and the overall letter grade in the class. It is suggested that the students who are capable enough to be placed directly into Calculus I probably possess the abilities to pass the class. Those who must take pre-requisite courses to reach Calculus I typically do not attain the necessary aptitude and understanding, leading to those students either struggling in or failing Calculus I.

The overwhelming majority of the students felt that having prior exposure to calculus was a benefit when taking Calculus I. However, none felt that this exposure was a necessity. Furthermore, the Pearson's Chi Square Tests indicated that prior exposure did not make a significant difference in students' grades. Any advantage that does exist appears to be short-lived. Looking further into the college careers of students, [6] found that "[s]tudents with more secondary school calculus background were more likely to continue to the second semester of college calculus than students with less secondary school calculus background" (p. 67). However, taking calculus during high school may not pay off as much in later calculus classes as during the first college course. [6] noted that any differences between the four groups (no high school calculus, a brief introduction to calculus, a year of non-Advanced Placement calculus, a year of Advanced Placement calculus) had vanished by the second semester.

Aside from replicating this study to either substantiate or refute its findings, the foundation for two future studies was established. The phenomenon of students changing their answers from the survey to the interview should be investigated, particularly in terms of what caused the changes and how often these changes of heart occur. The metacognitive findings from this study also call for further study. [12] found that good study habits had a stronger impact on remedial students when they did study than non-remedial students, but the weaker students typically spent less time studying than non-remedial students. They also found that encouragement also had a stronger influence on remedial students than on non-remedial students. The Calculus I students would be classified as non-remedial, but there may be similar results with a subgroup of less capable Calculus I students.

\section{References}

[1] Wieschenberg, A. A. (1994). Overcoming conditioned helplessness in mathematics. College Teaching, 42(2), 51-54.

[2] McDonald, K. (1987). Science and mathematics leaders call for radical reform in calculus teaching. Chronicle of Higher Education, 34(10), A1, A23.

[3] Bressoud, D., Rasmussen, C., Ellis, J., Larsen, S., Braddy, L., \& Johnson, E. (2016). Progress through calculus: National survey summary. Retrieved from

http://www.maa.org/sites/default/files/pdf/PtC\%20Survey\%20Rep ort.pdf.

[4] Bressoud, D. (2015, June 6). Calculus at crisis II: The rush to calculus [Web log post]. Retrieved from

http://launchings.blogspot.com/2015/06/calculus-at-crisis-ii-rushto-calculus.html.

[5] Burton, M. B. (1989). The effect of prior calculus experience on" introductory" college calculus. American Mathematical Monthly, 350-354.

[6] Ferrini-Mundy, J., \& Gaudard, M. (1992). Secondary school calculus: Preparation or pitfall in the study of college calculus?. Journal for Research in Mathematics Education, 56-71.

[7] Pyzdrowski, L., Pyzdrowski, A., Ogden, L., \& Walker, V. (2013). Indicators for success in first year calculus. Proceedings of The 11th Annual Hawaii International Conference on Education, USA. Retrieved from http://www.hiceducation.org/proceedings_edu.htm

[8] Pyzdrowski, L. J., Sun, Y., Curtis, R., Miller, D., Winn, G., \& Hensel, R. A. (2013). Readiness and attitudes as indicators for success in college calculus. International Journal of Science and Mathematics Education, 11(3), 529-554.

[9] Pyzdrowski, L., Ogden, L., Pyzdrowski, A., \& Walker, V. (2016). A longitudinal study of students in a dual-enrollment mathematics program: A focus on preparation for calculus. American Journal of Educational Research. 4(2), 204-209.

[10] Strauss, A., \& Corbin, J. (1990). Basics of qualitative research techniques and procedures for developing grounded theory. London: Sage Publications.

[11] Treisman, U. (1992). Studying students studying calculus: A look at the lives of minority mathematics students in college. College Mathematics Journal, 362-372.

[12] Hagedorn, L. S., Siadat, M. V., Fogel, S. F., Nora, A., \& Pascarella, E. T. (1999). Success in college mathematics: Comparisons between remedial and nonremedial first-year college students. Research in Higher Education, 40(3), 261-284. 